\title{
Validation and Quality Assurance of Ascorbic Acid Determination in Agricultural Products
}

\author{
ONDREJ HEGEDUS ${ }^{1}$, KATARINA SZARKA², ALZBETA HEGEDUSOVA ${ }^{3}$, ZSUZSANNA GODANY ${ }^{1}$, MIROSLAV SLOSAR ${ }^{3}$, \\ AURELIA CRISTINA NECHIFOR ${ }^{5}$, SZENDE TONK ${ }^{6 *}$ \\ 1]. Selye University Faculty of Economics in Komarno, Hradna 21, 94501 Komarno, Slovakia \\ 2]. Selye University Faculty of Education in Komarno, Bratislavska cesta 3322, 94501 Komarno, Slovakia \\ 3Slovak University of Agriculture in Nitra, Horticulture and Landscape Engineering Faculty, Department of Vegetable Production, \\ Tr. A. Hlinku 2, 94976 Nitra, Slovakia \\ ${ }^{4}$ Politehnica University of Bucharest, Faculty of Applied Chemistry and Materials Science, Analytical Chemistry and Environmental \\ Engineering Department, 1-7 Gheorghe Polizu Str. ,011061, Bucharest, Romania \\ 5Sapientia Hungarian University of Transylvania, Faculty of Sciences and Arts, 4 Calea Turzii, 400193, Cluj-Napoca, Romania
}

\begin{abstract}
The study describes a method for the determination of ascorbic acid $(A A)$ with the technique of high performance liquid chromatography with UV detection (UV-HPLC) modified for routine analysis of agricultural products. For successful use of the method in the test laboratory practice, the reliability of using this method has been confirmed by validation. The repeatability of method has been observed, which is $2.80-5.55 \%$ for the various crops. Relative combined standard uncertainty has a value of $6.2 \%$. The accuracy of the method is $103.2 \%$ and calculated as recovery of the standard addition. The value of the LOQ computed from the upper limit of reliability is $26.7 \mathrm{mg} \mathrm{kg}^{-1}$, which ensures safe determination of $A A$ in every major agricultural crop.
\end{abstract}

Keywords: ascorbic acid, agricultural products, determination, method validation, quality assurance

Ascorbic acid (AA) is one of the most important vitamins in human nutrition. Its vitamin nature is determined by Lascorbic acid and its oxidized form dehydroascorbic acid, while the total vitamin C content is defined as the sum of the two forms. In some agricultural products (especially broccoli), it is also present in a bound form known as ascorbigen $[1,2]$. Studies have shown, that the response of plants to air pollutants is influenced by the relationship between ascorbic acid levels and ozone susceptibility from different geospheres [3]. Ozone has a high oxidative potential, causing crop yield reductions, and also influencing the chemical composition of precipitation [410].

Reliable determination of its content in different foods is important for food quality control authorities, both science and research, and also consumers. For the purpose of food quality control it is important to have reliable analysis data that are sometimes problematic in different biological materials [11, 12]. In the European Union for official control of food applies the Regulation, E.C. 882/2004 [13], according to which it may be carried out by official laboratories, which must be accredited for this activity. Accreditation means that laboratories have an established and maintained quality system according to ISO/IEC 17025 [14], which is related to the necessity of validation, resp. verification of analytical methods in laboratory conditions.

Weak correlation of the results of analyses obtained in different laboratories may be attributed to the different specifics of the relevant method for vitamin C congeners, instability of the ascorbic acid atelevated pH, autocatalysis during extraction butalso limited detection sensitivity [15].

The heterogeneity of food matrices and the potential degradation of this vitamin during its analysis give rise to considerable challenges in the development of methods. Fruitjuices are often analysed directly or diluted with water, semi-solid matrices are dispersed in water and filtered [16] .
Without modifying the method specific for the observed matrix, vitamin C may be overestimated or underestimated in many foods. Problems arising from the specificity of the analysed matrix can be solved by thorough validation of the method for different matrices, which may differ from one another, by the $\mathrm{pH}$ value, and other qualitative parameters [17, 18].

Problems can also be caused by lability of L-ascorbic acid, which is a decisive factor in analyses. Its stability is greatly affected by the $\mathrm{pH}$ of the environment and the possibility of oxidation. In this respect, the processing of the sample is critical, especially during extraction.

The relative stability and extraction yield is achieved at a $\mathrm{pH}$ of value about 2.1 [19]. Therefore it is preferable to carry out the extraction with an acid because in an alkaline environment ascorbic acid is easily oxidized. Degradation enzymes also reduce the concentration of ascorbic acid; therefore their inactivation is suitable [20]. For these reasons, metaphosphoric acid, trichloroacetic acid, oxalic acid, or citric acid is often used for extraction, each of which acts as a stabilizer of ascorbic acid [17, 19-22].

Another important factor influencing the stability of ascorbic acid in the solution is temperature and light. Studies show that ascorbic acid extraction is best realized at low temperatures and with cooled solution or on ice [23]. It is recommended to perform operations in dimmed light or using amber glass and it is important to keep all solutions out of direct light [24].

For complex information on the composition of the analysed sample it is appropriate that the test method is able to determine the total vitamin C content ( $\mathrm{L}$-ascorbic acid and dehydroascorbic acid).

This requirement can be achieved if the reduced form of vitamin C is stabilized, or the oxidized form is reduced e.g. with dithiothreitol, L-cysteine [25], homocysteine, or tris (2-carboxyethyl) phosphine (TCPE), thus dehydro- 
ascorbic acid is reduced to ascorbic acid [26]. The total vitamin $\mathrm{C}$ content is determined as ascorbic acid by the HPLC-UV method [16, 17].

Currently, liquid chromatography (LC) methods are most often used to determine AA.

Most LC methods are based on the separation of AA on the reverse phase using a low $\mathrm{pH}$ mobile phase. In this environment, which is more acidic than the dissociation constant (pK) of $A A$, its tarry on the colony is improved $[12,27,28]$. Both ion-pair chromatography and ionexclusion chromatography $[29,30]$ are also used to determine ascorbic acid and dehydroascorbic acid. For determination of $A A$, the most widespread method is UV detection, resp. diode array detection (DAD) [19, 23, 31].

Despite the expansive use of $\mathrm{LC}$ for the determination of vitamin C in foodstuffs [12,16,19,32,33] and even, there is currently no official standard LC method for determining vitamin $\mathrm{C}$ in various food matrices. There are several common shortcomings of the methods used: absence of specificity, insufficient AA extraction or its stabilization during analysis, and insufficient confirmation of complete separation of AA from specific interferences in food in chromatographic analyses [17].

The aim of our work was to optimize the determination of vitamin C by the UV-HPLC method in plant-based agricultural products.

\section{Experimental part}

\section{Chemicals and reagents}

L-ascorbic acid (CertiPUR, Merck, Darmstadt, Germany) was used for preparation of standard solutions. All other reagents were of analytical reagent grade.

Chemicals for the mobile phase $\left(\mathrm{K}_{2} \mathrm{HPO}_{4}, \mathrm{KH}_{2} \mathrm{PO}_{4}\right.$ and $\mathrm{H}_{3} \mathrm{PO}$ ) and for Carrez clarifying agents ('Carrez $\mathrm{I}_{\mathrm{A}}: \mathrm{K}_{4}$ ) $\mathrm{Fe}(\mathrm{CN})_{6}$ and Carrez II: $\left.\mathrm{ZnSO}_{4}\right)$ were also purchased from Centralchem (Bratislava, Slovakia). Deionized water was used to prepare all solutions.

\section{Instrumentation}

Determination of ascorbic acid was performed with a WATERS HPLC system: Waters 2489 UV/VIS Detector, Waters 1525 Binary HPLC Pump, used in isocratic elution mode for ascorbic acid determination at $264 \mathrm{~nm}$, and a 20 $\mu \mathrm{L}$ sample loop. Waters Empower 2 software was used.

Separation was carried out on a GraceSmart RP 18 column (lenght $150 \mathrm{~mm}$, i.d. $4.6 \mathrm{~mm}$, particle size $5 \mu \mathrm{m}$, Chromservis s.r.o., Czech Republic).

The operating conditions were as follows: a mobile phase was prepared as a $1.9 \mathrm{~g} \mathrm{~K}_{2} \mathrm{HPO}_{4}$ and $2.5 \mathrm{~g} \mathrm{KH}_{2} \mathrm{PO}_{4}$ dissolved in $1000 \mathrm{~mL}$ deionized water. If necessary, the $\mathrm{pH}$ was adjusted to 3.5 with $\mathrm{H}_{3} \mathrm{PO}_{4}$. The mobile phase flow was $0.5 \mathrm{~mL}$ min-1, maximum working pressure was 800 PSI and injected sample volume was $20 \mu \mathrm{L}$. The analysis was made for the determination ascorbic acid by direct photometric detection.

Chromatographic signals were evaluated by measuring the peak area. The instrument was calibrated with five mixed standards in the range $5.0-25.0 \mathrm{mg} \mathrm{L}^{-1}$. Calibration was performed prior to each use. We adopted a linear model to evaluate the calibration response.

\section{Samples and sample preparation}

Sea buckthorn (Hippophae rhamnoides), green pepper (Capsicum annuum), sweet potato (Ipomoea batatas), squash (Cucurbita moschata) and Cranberry (Vaccinium oxycoccos) were used for analysis.

The average sample was created from the analysed vegetal materials by slicing them into tiny bits, and from this sample $100 \mathrm{~g}$ were weighed and $100 \mathrm{ml}$ of oxalic acid
( $2 \mathrm{~g}$ per $100 \mathrm{~mL}$ ) was added and homogenized. After then $20 \mathrm{~g}$ of homogenized mixture and $50 \mathrm{ml}$ of oxalic acid (2 $\mathrm{g}$ per $100 \mathrm{~mL}$ ) were added into $100 \mathrm{~mL}$ volumetric flask and AA was extracted at room temperature $10 \mathrm{~min}$. in an ultrasonic shaker. Then Carres I and II solutions (Carres I: $\mathrm{K}_{4} / \mathrm{Fe}(\mathrm{CN})_{6}, 150 \mathrm{~g}$ per $1.000 \mathrm{~mL}$; Carres II: ZnSO ${ }_{4}, 300 \mathrm{~g}$ per $1.000 \mathrm{~mL}$ ) were applied as clearing agents using $1 \mathrm{~mL}$ from each solution.

For the quantitative assessment of the results of the analyses the method of calibration curve was used in the range of linear response of AA. The calibration curve is prepared on 5 concentration levels of the standards Lascorbic acid. From the measured areas of the chromatographic peak standards depending on the concentration of the standards the regression line was calculated. If necessary, the sample was adequately diluted with oxalic acid ( $2 \mathrm{~g}$ per $100 \mathrm{~mL}$ ) in order that the content of the analyte was within the range of the calibration curve.

Internal reference material (standard addition of Lascorbic acid in an amount $1000 \mathrm{mg}$ per L) was prepared using the same procedure.

\section{Validation of the Method}

The results of the analyses were statistically processed and the validation parameters calculated by the work Hegedûs, et al. [34]. We describe the reliability of the method in the following parameters:

The stability of extract has been studied over a $6 \mathrm{~h}$ stall of the extract.

Repeatabilityas a relative standard deviation (RSD) from repeated measurements of a real sample,

Accuracy was evaluated as recovery by standard addition to the real carrot sample followed by repeated measurement.

Linearity was evaluated as the method's ability to obtain test results, which are directly proportional to the concentration of analyte in the sample.

Limit of detection (LOD), limit of quantitation (LOQ) were calculated from calibration dependence. Evaluation of results by the calibration curve was made by calculation of the limit of detection and limit of quantitation from the upper limit approach (ULA) [35]. The upper limitapproach, calculates the upper confidence limit of an individual blank signal using a critical value of the t-distribution and standard error of estimate (residual standard deviation) of regression.

Uncertainty of the analytical method was expressed as an expanded uncertainty and was calculated in program Metro2003 [36].

\section{Results and discussions}

From the point of view of the analysis of AA samples of agricultural products are among the complex matrix. The entire procedure for the determination, including the preparation and processing of samples, requires good agility and skill.

The greatest risk of oxidation of $A A$, thereby reducing its content occurs during homogenizing of samples, in particular in the analysis of fresh, respectively frozen plant material. The risk of oxidation also increases by reducing the acidity of the samples. For these reasons, it is appropriate for the material to be analysed in the shortest time interval to convert into the extraction reagent with a low $\mathrm{pH}$ [19]. For the extraction of AA from the plant material, it is important to choose extraction reagent to ensure proper extraction of the $A A$, and the extraction conditions adjusted to a reasonable time that was the most perfect for extraction. 
As for the extraction of AA acid environment is the most suitable, in our work, we have chosen as the extraction reagent $2 \%$ solution of oxalic acid.

By using the $2 \%$ solution of oxalic acid the $\mathrm{pH}$ of the plant extract is 2.3. $2 \%$ solution of oxalic acid ensures a good extraction of $A A$, and it served as a stabilizing factor against the oxidation-reduction processes. We ensured thorough extraction of AA by homogenization of plant samples in a solution of $2 \%$ solution of oxalic acid and then placing the containers with the mixture of homogenized sample and extraction reagent in the ultrasonic bath for 10 min. After extraction, we filtered the mixture through a thick filter paper and we used the extract for analysis. HPLC is a frequently used method for the determination of $A A$ in plant material [16, 17].

Detection within UV range is the most commonly used method of determination, which we also used in our work. figure 1 shows the chromatogram AA, obtained by that method.

Validation of the method was carried out to the extent described in the chapter Material and method, and was carried out for the verification of reliability of the method. Our results showed the reliable use of the method. The calculation of each validation of the parameter requires the results of analysis AA from the series of samples. The calculation is made in table calculator in program Excel.

The results of the analyses show the stability of the prepared extract in table 1, where changes to the contents of the AA in the extract of sea buckthorn are listed.

The results of the validation are indicated in tables 1 through 3, resp. in pictures 2 to 4 . During the optimization methods as first we watched the stability of extract, prepared by the procedure described in section Material and method.

The results of the analyses in prepared extracts show that after 4 hours of standing still under laboratory conditions $\left(\mathrm{t}=22^{\circ} \mathrm{C}\right)$ there is no significant change in the contents of the AA. The slight drop came up after $6 \mathrm{~h}$ of stalling of the

Table 1

CHANGES IN THE CONTENT OF ASCORBIC ACID DURING STALLING OF SEA BUCKTHORN EXTRACT

\begin{tabular}{|c|c|c|}
\hline $\begin{array}{c}\text { Time } \\
(\mathrm{h})\end{array}$ & $\begin{array}{c}\text { Content AA } \\
\left(\mathrm{mg} \mathrm{kg}^{-1}\right)\end{array}$ & $\begin{array}{c}\text { Retention } \\
(\%)\end{array}$ \\
\hline $\mathbf{0}$ & 2016 & 100.0 \\
\hline $\mathbf{2}$ & $2011^{-}$ & $99.8^{-3}$ \\
\hline $\mathbf{4}^{-}$ & $2011^{--}$ & 99.8 \\
\hline $\mathbf{6}^{-}$ & $1945^{-}$ & 96.5 \\
\hline
\end{tabular}

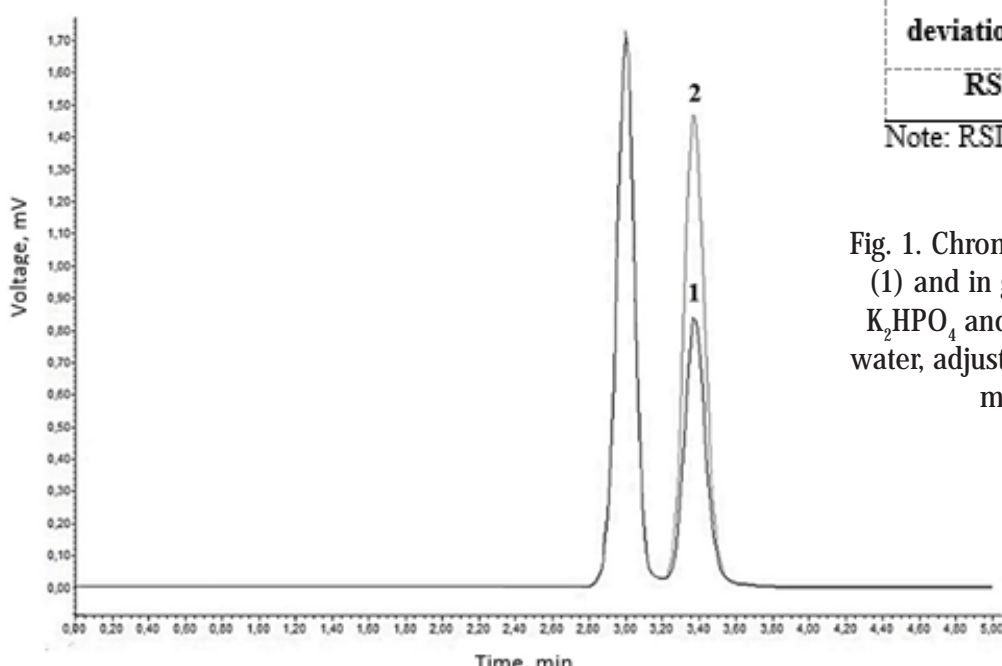

Time, $\min$

extract. This means that during the procedure according to a prescribed workflow, where individual tasks follow each other without unnecessary stall, the contents of the extracted AA do not change.

Table 2 shows the results of the analyses of fresh red peppers and sea buckthorn for calculation of repeatability. The listed plant species have been selected due to the differences in the difficulty of preparing a homogeneous sample for extraction. While it is easier to prepare a homogeneous sample from the juicy small fruit of sea buckthorn, the fruit of the pepper are characterized by different amounts of AA in different parts of the fruit, and also the fruits of paprika are characterised by a very significant individual variability of AA in different fruits, which significantly make difficulties in the preparation of a homogeneous sample. The repeatability requirement was less than $10 \%$.

According to the obtained results, the method is characterized with acceptable repeatability $(5.55 \%$ for red pepper and $2.80 \%$ for sea buckthorn). Different values can be caused by the preparation of an average sample of those commodities. The results indicate that the method can be used with an acceptable repeatability to establish AA in various crops. Our results of repeatability are similar to the [37] method, when they achieved the intra-and inter-day instrument precisions for fruit juices and 2.4\% 2.2\% for HPLC method. For the various kinds of analysed vegetable

Table 2

THE REPEATABILITY OF THE METHOD IN THE EXAMPLE, THE ANALYSIS OF FRESH RED PEPPERS AND SEA BUCKTHORN

\begin{tabular}{|c|c|c|}
\hline $\begin{array}{l}\text { The number } \\
\text { of analyses }\end{array}$ & $\begin{array}{l}\text { Ascorbic acid } \\
\text { in red pepper } \\
\left(\mathrm{mg} \mathrm{kg}^{-1}\right)\end{array}$ & $\begin{array}{l}\text { Ascorbic acid in } \\
\text { sea buckthorn } \\
\left(\mathrm{mg} \mathrm{kg}^{-1}\right)\end{array}$ \\
\hline 1. & 1741 & 1542 \\
\hline 2 . & $1741^{-}$ & 1518 \\
\hline 3. & $1750^{\circ}$ & 1613 \\
\hline 4. & 1755 & 1637 \\
\hline 5. & 1933 & $1643^{-}$ \\
\hline 6. & $1958^{-}$ & 1638 \\
\hline 7 & $1943^{-}$ & 1633 \\
\hline 8. & 1938 & 1630 \\
\hline 9. & $1750^{\circ}$ & 1633 \\
\hline 10. & 1749 & $1647^{-}$ \\
\hline Average & 1826 & 1613 \\
\hline $\begin{array}{l}\text { Standard } \\
\text { deviation }\end{array}$ & 101 & 45.2 \\
\hline RSD, \% & 5.53 & $2.80^{\circ}$ \\
\hline
\end{tabular}

g. 1. Chromatograms of ascorbic acid in standard solution 1) and in green pepper extract (2). Mobile phase: $1.9 \mathrm{~g}$ $\mathrm{K}_{2} \mathrm{HPO}_{4}$ and $2.5 \mathrm{~g} \mathrm{KH}_{2} \mathrm{PO}_{4}$ dissolved in $1000 \mathrm{~mL}$ deionized $\min ^{-1}$, and injection volume was $20 \mu \mathrm{L}$. 


\begin{tabular}{|c|c|}
\hline \multicolumn{2}{|l|}{ Peak area $(\mathrm{Ax})$} \\
\hline & Repeated analysis \\
\hline & Uncertainty for loop \\
\hline & Uncertainty of integration \\
\hline & Temperature correction \\
\hline \multicolumn{2}{|c|}{ Intercept of the calibration curve (b) } \\
\hline & Uncertainty of intercept \\
\hline \multicolumn{2}{|c|}{ Purity of standard (ch) } \\
\hline & Uncertainty of purity \\
\hline \multicolumn{2}{|c|}{ Slope of the calibration curve (m) } \\
\hline & Uncertainty of slope \\
\hline \multicolumn{2}{|c|}{ Sample bulk (n) } \\
\hline & Uncertainty of weighing \\
\hline \multicolumn{2}{|c|}{ Extract volume (V) } \\
\hline & Calibration of $100 \mathrm{ml}$ volumetric flask \\
\hline & Temperature correction \\
\hline
\end{tabular}

Fig. 2. Ishikawa diagram of uncertainty calculation for used equation: $A A=(A x-b) *(1 / m) * c h * 1000 * V / n$
[17] published values of 1.1 to $4.8 \%$ repeatability.

The uncertainty of the method belongs to the basic statistical parameters of the analytical method. Uncertainty of method is an important statistic parameter of the analytical method, which has to be shown with the results of analytical determination. The parameter gives important information about the precision of the obtained result. For the calculation of the uncertainty of the method Ishikawa diagram was drawn up with the program Metro2003 [36] and it is illustrated in figure 2 .

The uncertainty of method calculated on the evidence established criteria on the Ishikawa diagram shall be as follows:

Determined value:

Combined standard uncertainty:

$\begin{array}{ll}\text { Relative combined standard uncertainty: } & 6.2 \% \\ \text { Relative expanded uncertainty: } & 12 \% \text {. }\end{array}$

The results of the uncertainty calculations show that that method is characterized by an acceptable uncertainty, and it is in accordance with the results of repeatability.

Accuracy is defined as the closeness of agreement between the average value obtained from a large series of test results and an accepted reference value [38, 39], resp. as a share of the volume of present analyte or added to the analytical part of the test material, which is extracted and used on the measure [40].

In our work we evaluated the accuracy of methods according to the IUPAC/ISO/AOAC (1996) as recovery of a standard addition to the nature of the sample. The results of the analysis are presented in table 3.

Values of the recovery of the assessment for accuracy are generally acceptable with values between 81 and $109 \%$ [33]. On the basis of analysis sea buckthorn without or with the standard addition (table 4) we calculated 103.2 $\%$ recovery, which we consider to be a very acceptable value. The analytical results after standard addition were obtained with a selection variation coefficient $(\mathrm{RSD}=$ $3.70 \%$ ), which does not exceed the repeatability specified in table 2. A similar average recovery value is published by [17] when the value obtained ranged from $97-103 \%$.

Based on the fact, that the AA content was calculated from the calibration curve, we evaluated the linearity of the calibration dependence in the range of use for the analysis of agricultural products [34]. The linearity of the method is guaranteed in the whole range of the calibration curve (fig. 3).

\begin{tabular}{|c|c|c|c|c|}
\hline \multirow[t]{2}{*}{$\begin{array}{c}\text { The number of } \\
\text { analyses }\end{array}$} & \multicolumn{3}{|c|}{$\begin{array}{l}\text { AA content } \\
\left(\mathrm{mg} \mathrm{kg}^{-1}\right)\end{array}$} & \multirow[t]{2}{*}{$\begin{array}{c}\text { Recovery } \\
(\%)\end{array}$} \\
\hline & $\begin{array}{l}\text { Sea buckthorn without } \\
\text { the addition }\end{array}$ & $\begin{array}{l}\text { Sea buckthorn } \\
\text { after the addition } \\
\text { of standard }\end{array}$ & $\begin{array}{l}\text { The concentration of the } \\
\text { standard }\end{array}$ & \\
\hline 1. & 1715 & 2737 & 1022 & 102.2 \\
\hline 2. & $1733^{-}$ & 2982 & 1249 & 124.9 \\
\hline 3. & $1740^{--}$ & $2775^{--1}$ & $1034^{--}$ & $103.4^{-1}$ \\
\hline 4. & 1731 & $2751^{-}$ & 1019 & $101.9^{-1}$ \\
\hline 5. & 1731 & $2752^{-}$ & $102 \sigma^{-}$ & 102.0 \\
\hline 6. & 1728 & $2759^{--}$ & 1031 & 103.1 \\
\hline 7. & 1736 & 2827 & 1091 & 109.1 \\
\hline 8. & $1748^{-}$ & 2536 & 788 & $78.8^{-\cdots}$ \\
\hline Average & 1733 & 2765 & 1032 & 103.2 \\
\hline $\mathrm{RSD}, \%$ & - & $3.70^{-}$ & - & - \\
\hline
\end{tabular}

Table 3

DETERMINATION OF THE RECOVERY OF METHOD OF THE

ADDITION OF STANDARD CONCENTRATION $1000 \mathrm{mg} \mathrm{kg}^{-1}$ 


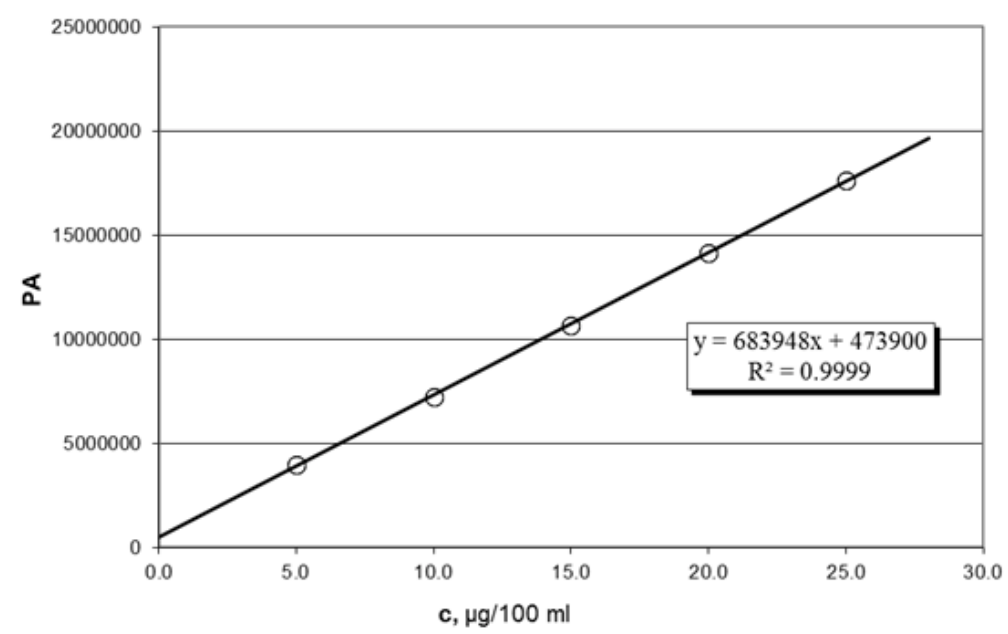

Fig. 3. Calibration curve for the determination of ascorbic acid. (PA - peak area, c - concentration of $A A, R^{2}$ - coefficient of determination)

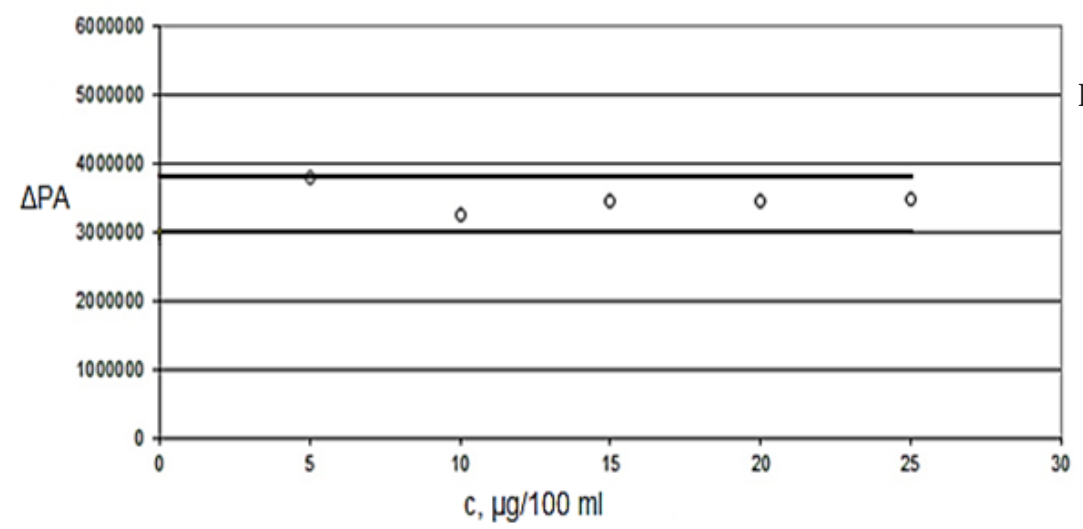

Fig. 4. Equal signal increment depending on increase of AA concentration in equidistant separation. $(\triangle P A$ - peak area increase after concentration increase, $c$ - concentration of AA)

The linearity of the calibration curve was tested by observing a regular increase in the ÄPA signal, depending on the increase in AA concentration in the equidistant separation (fig. 4). In the case of linear dependence, ÄPA is the same for each concentration increase. Since the signal response for each concentration leap in the equidistant division of the calibration curve is between the upper and lower acceptability limits $( \pm 12 \%$, which is the relative expanded uncertainty of the method), the linearity conditions are perform. It shows also a good linear dependence calculated coefficient of determination $R^{2}=$ 0.9999 (fig. 3). Based on the above, we can say, that the linearity is ensured throughout the calibration dependence.

Limit values for determination have a very important role in the development of the analytical method. In our work we have calculated limit values of limit of detection (LOD) and limit of quantification (LOQ). There are several ways to calculate them, and the calculation method significantly affects the resulting numerical values. To calculate these values, we used a calculation method from the residual standard deviation of the calibration curve [35], which will ensure to get real usable values of these parameters for a specific range of calibration in routine analysis.

Based on the requirement, to ensure determination of all significant $A A$ content in agricultural plant products, the requirement for LOD value was less than $10 \mathrm{mg} \mathrm{AA} \mathrm{kg}^{-1}$ of the analysed sample, from which it follows, that, in the definition [35] the LOQ should have a maximum of three times this value, i.e., less than $30 \mathrm{mg} \mathrm{AA} \mathrm{kg}^{-1}$ of the analysed sample.

These values from the practical point of view are sufficient, concentrating on the lower limit values for the analysis of agricultural crops in the routine analysis does not have practical significance.

Solving the equations for the described extraction $\mu \mathrm{g}$ per $100 \mathrm{~mL}^{-1}$, (in terms of the analysis $8.9 \mathrm{mg} \mathrm{kg}^{-1}$ of the test sample) and a $\mathrm{LOQ}=0.54 \mu \mathrm{g}$ per100 $\mathrm{mL}^{-1}$, (in terms of the analysis $26.7 \mathrm{mg} \mathrm{kg}^{-1}$ of the test sample). The calculated value of LOD and LOQ are lower than the given requirement for routine analysis of agricultural products, therefore, they are acceptable and ensure a reliable analysis of the samples, even with relatively low content of AA.

It is important to note, that the limitvalues are applicable to the determination of the conditions, and in particular are dependent from the weighed quantity of samples and dilutions. The amount of weighed samples and dilution is possible to change it significantly. For routine analysis of fruit products and foods [16] prepared a routine method for the determination of vitamin $\mathrm{C}$ by liquid chromatography, where the lower limit of determination marked at $5 \mathrm{mg}$. $100 \mathrm{~g}$ of sample, i.e. $50 \mathrm{mg} \mathrm{kg}^{-1}$. By comparison with our results it's the value of 1.9 times higher than calculated by us. [37] set the LOD value $0.049 \mu \mathrm{g} \mathrm{mL}^{-1}$ and the value of the LOQ $0.149 \mu \mathrm{g} \mathrm{mL}^{-1}$ for HPLC analysis of AA, which is significantly higher than we have identified. In contrast, [17] in pursuance of validation set value LOD $0.06-0.09$ $\mathrm{mg}$ per $100 \mathrm{~g}$ of the food and LOQ $0.2 \mathrm{mg} \mathrm{AA}$ per $100 \mathrm{~g}$, which calculated to $\mathrm{kg}$ the sample to be analysed is 0.6 $0.9 \mathrm{mg}$ per LOD and $2.0 \mathrm{mg}$ per LOQ.

These values are significantly lower than we have found.

For objective evaluation methods according to the LOD and $L O Q$, you must remember that to compare the value of LOD and LOQ from different authors without knowing the exact conditions of the analysis and the method of calculating these values are not correct. It is important to assess whether the method used complies with the intended use.

To verify the applicability of the method for analysis described in this validated method we used to establish AA in different kinds and varieties of agricultural products. The results of the analysis are presented in table 4. conditions we have set the following values: $L O D=0.18$ 


\begin{tabular}{|l|c|c|}
\hline Type & $\begin{array}{c}\text { Content AA } \\
\text { mg kg-1 }\end{array}$ & $\begin{array}{c}\text { RSD } \\
\%\end{array}$ \\
\hline Sweet potato variety Dubajská & 459 & 3,4 \\
\hline Sweet potato variety Višnjica fialová & 241 & 4,7 \\
\hline Squash variety Liscia & 133 & 3,5 \\
\hline Red pepper variety Esperansa Fl & 1983 & 4,9 \\
\hline Red pepper variety Kapirex F1 & 1803 & 1,3 \\
\hline Cranberry, mixed varieties & 59 & 3,6 \\
\hline Common sea buckthorn, cultivar Hergo & 2956 & 2,1 \\
\hline Common sea buckthorn, cultivar Lekora & 1422 & 3,5 \\
\hline Sea buckthorn juice after heat treatment & 2747 & 0,72 \\
\hline
\end{tabular}

Table 4

CONTENT OF ASCORBIC ACID IN DIFFERENT AGRICULTURAL CROPS
Based on the results of the analyses it is obvious that the above method is successful in analysing products of different composition, and in each case the results of repeatability are in accordance with the results of the validation.

On the basis of the achievements the method may be recommended for testing laboratories that use HPLC technique in their own procedures. By including the appropriate separation column they may apply this technique to determine AA. The analysis does not require complicated sample preparation and is suitable for routine analysis of agricultural plant products.

\section{Conclusions}

HPLC method for the determination of AA described in our work was subjected to validation. The method is described by the following characteristics of validation: used extraction reagent ( $2 \%$ oxalic acid) ensures the stability of extracted AA during 4 hours. The established repeatability of the method was a $2.80-5.55 \%$, which is consistent with our requirements. Relative combined standard uncertainty is $6.2 \%$.

We calculated the accuracy of the method as the recovery of the standard addition and we set the value of $103.2 \%$.

The linearity of the calibration is guaranteed throughout the range of the used calibration curve. The value of the LOQ computed from the upper limit of reliability is 26.7 mg kg-1, which ensures safe determination of AA in every major agricultural crop. The described method was successfully applied to the determination of the $A A$ in several kinds of agricultural products.

The results of the work confirmed that the described method of determining the AA can be successfully used for routine analysis of agricultural products, which are a major source of AA.

Acknowledgements: The work was supported by VEGA project No. 1/ 0087/17: Lesser-known species of horticultural crops as potential sources for production of food with increased content of chemoprotective compounds.

\section{References}

1. OSTER, B., FECHTEL, U. Vitamins, 7. Vitamin C (I Ascorbic Acid). Ullmann's Encyclopedia of Industrial Chemistry, 2000.

2. SMIECHOWSKA, A., BARTOSZEK, A., NAMIE氏ENIK, J Postêpy Hig. Med. Doœw, 62, 2008, p. 125-140.

3. MENSER, H. A., Plant Physiol, 39, no. 4, 1964, p. 564-567.

4. SZEP, R., MATYAS, L., KERESZTES, R., GHIMPUSAN, M., Rev. Chim., 67, no. 2, 2016, p. 205-213.
5. SZEP, R., KERESZTES, R., CONSTANTIN, L., Rev. Chim.(Bucharest), 67, no. 3, 2016, p. 408-413.

6. SZEP, R., KERESZTES, R., TONK, Sz., KORODI, A., CRACIUN, M. E., Rev. Chim.(Bucharest), 68, no. 4, 2017, p. 642-645.

7. SZEP, R., MATEESCU, E., NECHIFOR, A. C., KERESZTESI, A., Environ. Sci. Pollut. Res., 24, no. 35, 2017, p. 27288.

8. SZEP, R., MATEESCU, E., NITA, A., BIRSAN, M., BODOR, Z., KERESZTESI, A., Atmos. Res., 214, 2018, p. 311-328, doi: 10.1016/ j.atmosres.2018.08.009.

9. KERESZTESI, A., PETRES, S., GHITA, G., DUMITRU, F. D., MONCEA, M. A., OZUNU, A., SZEP, R., Rev. Chim.(Bucharest), 69 , no. 1, 2018, p. 57-63.

10. SZEP, R., BODOR, Z., MIKLOSSY, I., NITA, I.A., OPREA, O.A., KERESZTESI, A., Sci. Total Environ., 647, 2019, pp. 275-289.

11. LIAU, L. S., et al. Journal of Chromatography B: Biomedical Sciences and Applications, 612, no. 1, 1993, p.63-70.

12. NOVAKOVA, L., SOLICH, P., SOLICHOVA, D. TrAC Trends in Analytical Chemistry, 27, no. 10, 2008, p. 942-958.

13. *** EU COMMISSION, et al. Official J ournal of the European Union L, 191, 2004, p. 1-52.

14.*** ISO, BSEN. IEC 17025: 2005. General requirements for the competence of testing and calibration laboratories.

15. LANDEN JR, W.O., EITENMILLER, Ronald R., YE, Lin., Vitamin analysis for the health and food sciences, CRC press, 2016.

16. BRAUSE, A. R., WOOLLARD, D.C., INDYK, H. E., J ournal of AOAC International, 86, no. 2, 2003, p. 367-374.

17. TARRAGO-TRANI, M. T., PHILLIPS, K. M., COTTY, M. Journal of Food Composition and Analysis, 26, 2012, p.12-25.

18. SCHERER, R., POLONI RYBKA, A.C., BALLUS, C. A., DILLENBURG MEINHART, A., TEIXEIRA FILHO, J., TEIXEIRA GODOY, H., Food Chemistry, 135, no. 1, 2012, p. 150-154.

19. HERNANDEZ, Y., LOBO, M. G., GONZALEZ, M. Food chemistry, 96, no. 4, 2006, p. 654-664.

20. VELISEK, J. Chemie potravin. Ossis, 2002.

21. TORREGROSA, F., ESTEVE, M.J ., FRIGOLA, A., CORTES, C., J ournal of Food Engineering, 73, no. 4, 2006, p. 339-345.

22. ODRIOZOLA-SERRANO, I., HERNANDEZ-JOVER, T., MARTINBELLOSO, O. Food Chemistry, 105, no. 3, 2007, p. 1151-1158.

23. RIZ7OLO, A. et al. Food Chemistry, 77, no. 2, 2002, p. 257-262.

24. CAMPOS-GIMENEZ, E. et al. J ournal of AOAC International, 96 , no. 5, 2013, p. 1065-1067.

25. EN 14130:2003. Foodstuff-determination of vitamin C by HPLC. 26. BEHRENS, W. A., MADERE, R. Analytical biochemistry, 165, no. 1, 1987, p. 102-107.

27. FEKETE, J . A folyadekkromatografia alapjai, J ava-98 Kft., Budapest, 2003.

28. ENGEL, R., STEFANOVITS-BANYAI, E., ABRANKO, L. Chromatographia, 71, 2010, p. 1069-1074.

29. KARLSEN, A., BLOMHOFF, R., GUNDERSEN, T. E. Journal of Chromatography, 824, 2005, p. 132-138. 
30. SALMINEN, I., ALFTHAN, G. Clinical biochemistry, 41, no. 9, 2008, p. 723-727.

31. KAFKAS, E., KOSAR, M., TUREMIa , N., BASER, K. H. C. Food Chemistry, 97, no. 4, 2006, p. 732-736.

32. BARROS, A.I., SILVA, A.P., GONCALVES, B., NUNES, F.M. Analytical and bioanalytical chemistry, 396, no. 5, 2010, p. 1863-1875.

33. SPINOLA, V., LLORENT-MARTINEZ, E. J., CASTILHO, P. C. J ournal of Chromatography A, 1369, 2014, p. 2-17.

34. HEGEDUS, O., HEGEDUSOVA, A., JAKABOVA, S., VARGOVA, A., PERNYESZI, T., BOROS, B. Chromatographia, 71, 2010, p. 93-97.

35. MOCAK, J., BOND, A. M., MITCHELL, S., SCOLLARY, G. Pure and Applied Chemistry, 69, no. 2, 1997, p. 297-328.
36. BARIEIE, P., MACKOV, M. Metro2003 (Verzia: 2.30). Laboratórny softver pre Windows. Chemmea sro, Bratislava Google Scholar, 2003. 37. KLIMCZAK, I., GLISZCZYNSKA-SWIGLO, A. Food chemistry, 175, 2015, p. 100-105.

38. BARTOLOMEO, M. P., MAISANO, F. J ournal of biomolecular techniques: JBT, 17(2), 2006, p. 131.

39. ISO 3534-1:2006. Statistics, vocabulary and symbols, part 1: general statistical terms and terms used in probability.

40. THOMPSON, M., ELLISON, S.L.R., FAJGELJ, A., WILLETTS, P., WOOD, R., Pure and applied chemistry, 71, no. 2, 1999, p. 337-348.

$\overline{\text { Manuscript received: } 19.03 .2019}$ 